\title{
Equity of access to long-term care among the Korean elderly
}

\author{
Ju Moon Park
}

Department of Urban Policy and Administration, University of Incheon, Incheon, South Korea; jumoonpark@incheon.ac.kr

Received 12 March 2011; revised 13 April 2011; accepted 14 May 2011

Copyright (C) 2013 Ju Moon Park. This is an open access article distributed under the Creative Commons Attribution License, which permits unrestricted use, distribution, and reproduction in any medium, provided the original work is properly cited.

\section{ABSTRACT}

The aim of the current study is to examine the extent to which equity in the utilization of longterm care services has been achieved in the Republic of Korea (hereafter Korea), based on the Aday-Andersen Access Framework that takes into consideration a series of variables hypothesized as predictive of utilization. The current study used cross-sectional survey data collected and conducted by the Korea Labor Institute (KLI) between August 1 to December 22, 2006. The sample for this study was $\mathbf{5 5 4 4}$ persons who are older than 60 years. The study was extracted from a larger nationally representative crosssectional survey of 10,255 individuals. The stratified cluster sampling technique was used to draw the survey respondents. A self-administered questionnaire was used to collect the data from the sample. Descriptive and logistic regression analysis was performed examining the relationship between the dependent variable and the independent variables and the relative importance of factors. The results indicate that a universal health insurance system has not yielded a fully equitable distribution of services. The limitation of benefit coverage as well as disparities in consumer cost-sharing and associated patterns of utilization across plans high out-ofpocket payment can be a barrier to health care utilization, which results in inequity and differential long-term care utilization between subgroups of older adults. Health policy reforms in Korea must continue to concentrate on expanding insurance coverage, reducing the inequities reflected in disparities in consumer cost-sharing and associated patterns of utilization across plans, and establishing a financially separate insurance system for poor older adults. The be- havioral responses of physicians to the method of reimbursement, and the subsequent impact on overall rates of utilization and expenditures need to be more fully understood. In addition, further research is needed to identify the nonfinancial barriers that persist for certain demographic subgroups, i.e., those $\mathbf{7 0}$ and older, men, lacking social network members, those who have four or more family members, and those who have no schooling.

Keywords: Equity of Access; Long-Term Care; Utilization; Korean Elderly

\section{INTRODUCTION}

The Republic of Korea (hereafter Korea) is becoming an aging society faster than any other country. The proportion of the elderly (65 years and older) in Korea was $11.4 \%$ in 2011 , but it is expected to rise to $15.7 \%$ by 2020 and $37.4 \%$ in 2050 [1]. In addition, functionally dependent older people aged 65 and over are estimated to make up $15 \%$ of the total population, but only about $1 \%$ of older people can afford to use formal services [2]. In response to the increased burden of supporting a frail older population, the Korean government implemented a long-term care program in 2008.

With the introduction of long-term care insurance, the long-term care service has been transformed from the very selective service applicable only to low-income groups to a universal service for all income groups. Also, the service provision method has been changed from the provision by nonprofit organizations entrusted by the state under a monopolistic commission arrangement in the past to a new open-service provision arrangement in which free competition among service providers in service market and consumers' choice will be emphasized [3]. This has caused the number of recipients of the long-term care insurance benefits to increase [4]. Projec- 
tions suggested by Korea Institute for Health and Social Affairs showed that the number of elderly receiving long-term care increased by 73\% between 2000 and 2010 [5].

With the rapidly growing long-term care beneficiaries, some researchers and policymakers have concern that this policy may have the unintended consequence of exacerbating disparities in care [4-6]. This concern is rooted in the realization that consumers from different socioeconomic groups may not have equal access to care due to differences in available resources. It is therefore anticipated that the findings of this study will be of value in identifying the subgroup differences in utilization and even more be of importance to decision makers in developing meaningful interventions that may alleviate some of the burden on the vulnerable subgroups with access problems.

The aim of this study is to examine the extent to which equity in the use of long-term care has been achieved in Korea. This study is guided by Aday and Andersen Access Framework, which has been broadly cited in studies of long-term care utilization [7-11]. In this study, equity of access to long-term care is measured based on the relative importance of need compared to the other determinants of long-term care utilization. Access is equitable to the extent that predisposing, need-related demographic factors such as age and sex, as well as illness, account for long-term care utilization. The demographic variables are included because of the well-established relationships between illness patterns and age and sex; hence, these measures may also serve as proxies for need in defining equity in this model. Inequity is suggested, however, if services appear to be distributed on the enabling variables, rather than need.

\section{METHODS}

\subsection{Sample}

The data come from the Korean Longitudinal Study of Ageing (KLoSA) conducted by the Korea Labor Institute (KLI) in 2008. The KLoSA is a longitudinal study of survey data from a nationally representative panel of Korean men and women aged 45 years or older. Baseline data were collected between July and November of 2008, and were analyzed using SAS for Windows 9.2 (SAS Institute Inc., Cary, NC). The sample for this study was 4040 individuals who indicated older than 65 years. The survey design was a 2-stage stratified cluster sampling framed by the national population and housing census. Trained interviewees visited randomly selected households nationwide excluding Jeju Island.

The survey had an $86.9 \%$ response rate. Non-responses were due primarily to failures to locate or contact individuals, failures of interviewers to obtain responses from individuals, or refusals of persons to participate in the survey.

For the analysis, the sample was weighted to reflect the population of the nation. To account for design effects created by stratified multistage cluster sampling, I used weights and strata in estimation.

\subsection{Utilization of Care}

Long-term care is a variety of services and supports to meet health or personal care needs over an extended period of time. In terms of the definition of long-term care utilization, this study uses the NLTCS ${ }^{1}$ definition that is the care for Activities of Daily Living (ADL) or Institutional Activities of Daily Living or (IADL), due to a disability or health problem for three months or more. Long-term care is needed when you have a chronic illness or disability that causes you to need assistance with ADL or IADL. Illness or disability could include a problem with memory loss, confusion, or disorientation. This is called Cognitive Impairment and can result from conditions such as Alzheimer's disease. The definition of cognitive impairment is based on the score on the MiniMental State Examination (MMSE). In the current study, I defined disability as having dependency in at least one ADL or IADL and defined a chronic illness as having severely cognitive impairments. The KLoSA has seven ADLs: dressing, washing, bathing, eating, getting out of the bed, toileting, and controlling urination and ten IADLs: doing housework, grooming in person, cooking meals, doing laundry, going places outside of walking distance, using transportation, shopping for groceries, managing money, making telephone calls, and taking medicine. The IADL items generally require both cognitive and physical capabilities. The responses for the ADL/IADL items are coded as either "yes" or "no", i.e., 0 or 1 . It is shown that $9.6 \%$ of the respondents used long-term care services and $90.4 \%$ did not.

\subsection{Independent Factors}

Health status, that is one of need factors, is not a well - defined concept, but it is widely used. Most previous research on determinants of health services utilization at older ages uses a small of set of indicators to measure different aspects of health status - the majority of these indicators focusing on physical limitations [12]. In addition to the physical dimension, aspects of emotional and cognitive health should simultaneously be considered. Research has indeed often shown significant impacts of

${ }^{1}$ The National Long-Term Care Survey (NLTCS) is a periodic nationally representative survey of persons aged 65 and older designed to identify elderly persons who are chronically disabled in one or more basic or instrumental activities of daily living (ADLs/IADLs). The NLTCS completed five waves, normally at five-year intervals, 1982, 1984, 1989, 1994, 1999, 2004, and 2009. 
emotional and/or mental disabilities on health services utilization [12,13]. The several measures of health status are all reported in an interview format, and range from the highly subjective (e.g. self-evaluation) to the more objective (e.g. conditions checked by a nursing assistant). In this study, three measures of health status are focused: 1) a self-evaluation of health as "good", or "poor/fair"; 2) a self-evaluation of restricted activity as "restricted" or "not restricted", 3) cognitive conditions based on the Mini-Mental State Examination (MMSE) which is most commonly used to assess an older person's mental status [14]. The definition of cognitive impairment is based on the score on the MMSE. The MMSE score ranges are used in the present analysis to determine which persons have cognitive impairment or not. In addition, if the interviewer was not able to talk directly to the sampled person because the person had Alzheimer's disease or any other form of dementia, then that person was classified as "having cognitive impairment".

In addition to health status of the elderly, health services utilization is closely related to demographic factors -in particular age and sex. As a consequence, age and sex are respectively represented as a dichotomy, i.e., "65 - 79" versus "80+" and "female" versus "male" in this analysis. Marital status is also closely related to health services utilization. Married persons are least likely to use health care services [7]. In this study, marital status is represented as a dichotomy, i.e., "married" (0) versus "unmarried or divorced or widowed" (1). The characteristic of social network, reflecting social conditions related to living arrangements, is also included in this study. The variable social network indicates having a regular contact with network members-the number of network members-including other family members, friends and neighbors. Previous studies show that having adult children is one of the best predictors of care $[15,16]$. In this study, social network is also represented by the dichotomous factor "having no regular contact with network members" (0) versus "having a regular contact with network members” (1).

A categorical factor indicating the level of education attained is used as a supplementary measure of socioeconomic status. In this study, education is represented by the binary factor, i.e., "middle school graduate or more” (0) versus "less than primary school graduate” (1).

The enabling factors are major predictors explaining health services utilization [7]. Personal and medical resources such as income and insurance coverage relate to service use. Income relates to long-term care, especially formal home care and institutional care. People with higher income tend to use more except those who spend down their assets to be eligible for Medicaid. In the present study, income refers to the total annual income after deduction for respondent. Income is represented by the dichotomous factor "more than 5,000,000 won (0)" to " $5,000,000$ won or less (1)". Economic theory suggests that in the presence of health insurance, the marginal cost of the insurance good is lower, thus increasing quantity demanded of the good. Medicaid guarantees continued consumption of formal nursing home care as well as home and community-based care, although on a somewhat more restrictive basis [17]. In the present study, health insurance refers to the insurance coverage the study subject used. Insurance coverage was categorized in 2 categories, i.e., "covered by medical aid” (0) versus “covered by health insurance” (1).

\subsection{Analysis Plan}

A series of bivariate analyses and associated chisquares was performed examining the relationship between each of the predisposing, enabling and need variables and long-term care utilization. Logistic regression analysis was then used to examine the relative importance of factors found to be significant in the bivariate analyses in predicting whether or not an individual used long-term care services.

To address the relative importance of the respective predisposing, enabling and need factors as predictors of utilization, the analyses were conducted in a series of stages. The predisposing variables were entered in stage 1 to examine demographic subgroup differences. The need variables were entered in stage 2 to examine the extent to which the subgroup differences in stage 2 were reduced when variations in the need for care were controlled. At the final stage, the enabling factors were entered to examine whether the remaining subgroup differences were due primarily to the availability of personal or medical care resources (stage 3).

The analyses will focus on subgroup differences in whether an individual used long-term care services in the two years preceding the interview, and a systematic series of multivariate (logistic regression) analyses examining the extent to which these differences are explained by equitable (need-related) or inequitable (non-need-related) factors.

\section{RERULTS}

\subsection{Bivariate Analysis}

Those who were most likely to have used long-term care services were 65 - 79 years, women, married, primary school graduates, had regular contact with network member, had no religion, persons with annual income of 5 million won or more, had health insurance, had poor health status, and had restricted activity and evident cognitive impairment (Table 1).

In the initial stage of the analyses, the variables such as age, sex, education, marital status, social work, relig- 
Table 1. Percentage of those who used long-term care services by each study variable.

\begin{tabular}{|c|c|c|}
\hline \multirow{2}{*}{ Study Variables } & \multicolumn{2}{|c|}{ Long-term care utilization } \\
\hline & Percentage & $\chi^{2}$ \\
\hline \multicolumn{3}{|l|}{ Predisposing } \\
\hline Age (years) & & $214.97^{\mathrm{a}}$ \\
\hline $80+$ & 4.05 & \\
\hline $65-79$ & 5.56 & \\
\hline sex & & 3.74 \\
\hline Male & 4.33 & \\
\hline Female & 5.27 & $14.44^{\mathrm{a}}$ \\
\hline \multicolumn{3}{|l|}{ Education } \\
\hline Primary school graduate & 7.43 & \\
\hline Middle school graduate + & 2.17 & $23.53^{\mathrm{a}}$ \\
\hline \multicolumn{3}{|l|}{ Marital status } \\
\hline Unmarried/divorced & 4.37 & \\
\hline Married & 5.23 & $6.41^{\mathrm{b}}$ \\
\hline \multicolumn{3}{|l|}{ Religion } \\
\hline Yes & 4.49 & $223.14^{\mathrm{a}}$ \\
\hline No & 5.12 & \\
\hline \multicolumn{3}{|l|}{ Social network } \\
\hline Regular contact & 6.61 & \\
\hline No regular contact & 2.99 & $262.55^{\mathrm{a}}$ \\
\hline \multicolumn{3}{|l|}{ Need } \\
\hline \multicolumn{3}{|l|}{ Self-perceived health status } \\
\hline Good & 1.67 & $217.36^{\mathrm{a}}$ \\
\hline Poor/Fair & 7.93 & \\
\hline \multicolumn{3}{|l|}{ Restricted activity } \\
\hline Yes & 8.14 & $209.89^{\mathrm{a}}$ \\
\hline No & 1.47 & \\
\hline \multicolumn{3}{|l|}{ Cognitive impairment } \\
\hline Yes & 8.22 & $44.24^{\mathrm{a}}$ \\
\hline No & 1.38 & \\
\hline \multicolumn{3}{|l|}{ Enabling } \\
\hline Income & & $29.37^{\mathrm{a}}$ \\
\hline Less than Won 5,000,000 & 1.68 & \\
\hline Won $5,000,000$ or more & 7.93 & \\
\hline Type of health plan & & $29.37^{\mathrm{a}}$ \\
\hline Health insurance & 8.05 & \\
\hline Medical aid & 1.56 & \\
\hline
\end{tabular}

${ }^{\mathrm{a}} p<0.01$; ${ }^{\mathrm{b}} p<0.05$; ${ }^{\mathrm{c}} p<0.1$; Note: The number of cases on which the estimates are based is 4040 , except for the following variable (for which the number of cases is noted in parentheses): age (4039).

ion, income, insurance coverage, self-perceived health status, restricted activity, and cognitive condition remained significant predictors of long-term care.
The significance level of $10 \%$ was used in this study to determine which independent variables would be included in the multiple logistic analyses, the multivariate phase of the analysis that follows.

\subsection{Multivariate Analysis}

The odds ratios for long-term care utilization, simultaneously adjusted for multiple independent variables, are presented in Table 2. After adjusting for an array of predisposing factors (stage 1), those who were less likely to have used long-term care services included older persons (especially those 80 and older), men, primary school graduates, those who are unmarried or divorced, and those who have no regular contact with network members-including friends, relatives, and neighbors.

These relationships were re-examined, adjusting for need (stage 2). The elderly with fair/poor health status, those who had restricted activity, and those who had evident cognitive impairment were much less likely than their counterparts have used long-term care services.

The need variables had a notable impact on the odds ratios of long-term care utilization for the predisposing variables entered in stage 2 . The demographic subgroup differences were in general narrowed in stage 2 . After the new set of need variables was added, the predisposing factors (age, sex, and social network) remained significant at the 0.01 level. After the new set of need variables was added, education and marital status became nonsignificant. Need factors such as health status, restricted activity, and cognitive impairment were then important determinants of long-term care utilization among old Koreans.

The impact of the enabling factors was examined in stage 3. Adjusting for the resource variable such as personal income and insurance had impact on the odds ratios of long-term care utilization for the predisposing and need factors. The remaining subgroup differences remained about the same once the resource variables were taken into account. After the new set of enabling variables was added, the need factor (self-perceived health status, restricted activity, cognitive impairment) which was significant in stage 2 remained significant at the 0.01 level.

In sum, having personal and health care resources, such as having personal income and insurance did not ameliorate the remaining subgroup differences in the use of long-term care services among old Koreans, observed in stage 2. Nonetheless, resource availability related to insurance and income remained important predictors of the use of long-term care services in Korea.

The chi-square based test for assessing how well the models fit the data was significant, i.e. $p<0.0001$ (Table 2). 
Table 2. Multivariate logistic regression analysis of predictors of long-term care services utilization for old Koreans, Weighted.

\begin{tabular}{|c|c|c|c|}
\hline \multirow{3}{*}{ Determinants } & \multicolumn{3}{|c|}{$<$} \\
\hline & Stage I & Stage II & Stage III \\
\hline & Odds Ratio $p$ & Odds Ratio $p$ & Odds Ratio $p$ \\
\hline \multicolumn{4}{|l|}{ Predisposing } \\
\hline Age (years) & $0.27<0.01$ & $0.36<0.01$ & $0.36<0.01$ \\
\hline \multicolumn{4}{|l|}{$80^{+}$vs. $65-79$} \\
\hline Sex & $0.56<0.01$ & $0.40<0.01$ & $0.37<0.01$ \\
\hline \multicolumn{4}{|l|}{ Male vs. Female } \\
\hline Education & $0.70<0.05$ & $1.20<0.27$ & $1.23<0.22$ \\
\hline \multicolumn{4}{|c|}{ Primary-school graduate vs. Middle-school graduate ${ }^{+}$} \\
\hline Religion & $1.01<0.94$ & $1.03<0.84$ & $1.03<0.81$ \\
\hline \multicolumn{4}{|l|}{ Yes vs. No } \\
\hline Marital status & $0.74<0.05$ & $0.79<0.12$ & $0.79<0.12$ \\
\hline \multicolumn{4}{|l|}{ Unmarried/divorced vs. Married } \\
\hline Social network & $4.49<0.01$ & $2.81<0.01$ & $2.67<0.01$ \\
\hline \multicolumn{4}{|c|}{ Regular contact vs. No regular contact } \\
\hline \multicolumn{4}{|l|}{ Need } \\
\hline Self-perceived health status & & $3.23<0.01$ & $3.18<0.01$ \\
\hline \multicolumn{4}{|l|}{ Good vs. Poor/Fair } \\
\hline Restricted activity & & $0.38<0.01$ & $0.40<0.01$ \\
\hline \multicolumn{4}{|l|}{ Yes vs. No } \\
\hline Cognitive impairment & & $0.24<0.01$ & $0.25<0.01$ \\
\hline \multicolumn{4}{|l|}{ Yes vs. No } \\
\hline \multicolumn{4}{|l|}{ Enabling } \\
\hline Income & & & $0.69<0.05$ \\
\hline \multicolumn{4}{|c|}{ Less than Won $5,000,000$ vs. Won $5,000,000$ or more } \\
\hline Type of health plan & & & $1.48<0.05$ \\
\hline \multicolumn{4}{|l|}{ Health insurance vs. Medical aid } \\
\hline Model chi-square & 393855.71 & 818810.19 & 832923.21 \\
\hline Degree of freedom & 6 & 9 & 11 \\
\hline Significance & $<0.0001$ & $<0.0001$ & $<0.0001$ \\
\hline
\end{tabular}

\section{DISCUSSION}

This study may be of use to those concerned with planning and operating the existing long-term care system and to those trying to redesign the Korean health care system through health care reforms. Given the rapidly growing older population in Korea and the increasing number of long-term care beneficiaries, more effectively targeting populations at risk is an essential part of both improving services to older adults and reducing disparities in care. Identifying the demographic subgroups that are least likely to use long-term care services is a first step in developing targeted health care interventions. Yet little work has focused on identifying how equitable the population subgroup differences might be. The research reported here addresses this issue.

As expected, health status and need were important determinants of the Korean elderly using long-term care services. Differences in need generally accounted for somewhat of the original differences observed between demographic subgroups. The results indicated that resources such as having insurance and personal income remained important independent predictors of access. Personal and health care resources did not however ameliorate the remaining subgroup differences in the use of long-term care among the Korean elderly. The results also indicated that certain subgroups, i.e., those 80 and older, men, and those who have no regular contact with network members are least likely to have used long-term care services, irrespective of need or resource availabil- 
ity.

An underlying expectation under the current system was that the Korean health care system would be equitable. The research reported here did not fully support this expectation. This is consistent with previous research [7], which has shown that the Korean health care system does not yield a fully equitable distribution of services. This may be due to the heavy copayment burden. High copayment leads to limited financial protection, and this can still be a barrier to long-term care utilization, which results in inequity and differential long-term care utilization across different socio-economic groups [18]. For example, compared to Japan with the $10 \%$ co-payment, a $20 \%$ co-payment appears to be too high considering the fact that individuals are already responsible for food and extensive service cost [19].

The health care system leaves the people relatively unprotected in time of financial crisis. Financial barriers to access become insurmountable for old Koreans at the bottom end of the income distribution. The findings that the poor and older Koreans with medical aid were less likely than their counterparts to use long-term care services provide evidence that they do not have full financial access to long-term care services under the current system. A financially separated system for poor older adults may be needed. However, the separation of longterm care financing from health insurance may be a barrier to the coordination between health care and longterm care when two different financing schemes try to dump their financial burden to the other [20]. Moreover, the disabled elderly may not be able to identify and express their needs explicitly such that selection of and linkage with the appropriate combination of health care and long-term care services may not be feasible. It is, therefore, important to construct an integrated delivery system that provides coordination between long-term and healthcare services [21]. Long-term care insurance provides coverage for long-term care for the elderly (aged 65 or above) and age-related long-term care of those younger than 65 years old. Korean long-term care insurance does not provide coverage for disability-related long-term care. Government has put policy priority on population aging and related problems, rather than aiming to solve problems related to long term care.

These findings are subject to the limitations of secondary data. The study did not fully operationalize the array of variables in the Aday and Andersen model. The conceptual model, as used in this study, was thus limited to the data collected by Korean Labor Institute in 2008 Therefore, the present study could not analyze the use of long-term care services, classifying by type. The long (1-year) recall period used to ask about service utilization can increase the amount of bias associated with respondent memory loss. Though the US National Center for Health Statistics National Health Interview Survey uses a 2-week recall period, that study is continuously in the field throughout the year, and data are used to construct aggregate estimates of volume of visits for the US population (National Center for Health Statistics, 1989). However, the Korean KLoSA uses a 2-year recall period and data are used to construct volume of visits estimates for individuals.

\section{CONCLUSION}

In conclusion, this study suggests that health policy reforms in Korea must concentrate on targeting the poor and older Koreans with medical aid and reducing the heavy copayment burden, and constructing an integrated delivery system that provides coordination between longterm and healthcare services. A financially separated insurance system that provides coverage not for age-related long-term care but for disability-related long-term care is also needed. In addition, further research is needed to identify the nonfinancial barriers that persist for certain demographic subgroups, that is, those 80 and older, men, those who lack a social network.

\section{ACKNOWLEDGEMENTS}

This work was supported by the Incheon National University Research Grant in 2012. A special word of thanks goes to the Korea Labor Institute which provided the data for this study.

\section{REFERENCES}

[1] Korean Statistics Office (2010) Population statistics. Korean Statistics Office, Daejeon.

[2] Duk, S. (2004) Long-term care policy for functionally dependent older people in The Republic of Korea. Health Affairs, 57, 47-62.

[3] Andersen, R.M. (1968) Behavioral model of families' use of health services. Research Series No 25, Centre for Health Administration Studies, Chicago.

[4] Duk, S. (2012) The present situation and problems of the long-term care insurance in South Korea: From comparative perspectives between South Korea and Japan. Japanese Journal of Social Security Policy, 9, 49-60.

[5] Jo, J.G. and Choi, K. (2011) Health policy in Korea. http://www.ier.hit-u.ac.jp/pie/Japanese/discussionpaper/d p2002/

[6] Flynn, M.L. and Chung, Y.S. (1990) Health care financing in Korea: Private market dilemmas for a developing nation. Journal of Public Health Policy, 11, 238-253. http://dx.doi.org/10.2307/3342754

[7] Park, J.M. (2005) The determinants of long-term care utilization and equity of access to care among older adults in Dong-Ku of Incheon metropolitan city, South Korea. Asia-Pacific Journal of Public Health, 17, 104-109. http://dx.doi.org/10.1177/101053950501700208 
[8] Lee, G.O. and Lee, M.J. (2001) The factors influencing the intention of using home health care among the Koran elderly. Korean Gerontologist, 21, 113-214.

[9] Song, D.Y. (2003) The factors influencing family caregivers' use of in-home services. Korean Society of Social Welfare, 53, 105-128.

[10] Lee, Y.K. (2009) The determinants of long-term care utilization among the elderly. Health and Social Welfare Review, 29, 213-235.

[11] Park, J.M. (2003) Equity of access to long-term care among the American elderly. Journal of Public Health, 11, 121-130. http://dx.doi.org/10.1007/BF02956148

[12] Stern, S. (1997) Simulation-based estimation. Journal of Economic Literature, 35, 2006-2039.

[13] Beekman, A., Deeg, D., Braam, A.W., Smith, J. and Van Tilburg, W. (1997) Consequences of depression in later life: Associations of major and minor depression with disability, well-being, and service utilization. Psychosomatic Medicine, 27, 1397-1409. http://dx.doi.org/10.1017/S0033291797005734

[14] Folstein, M.F., Folstein, S.E. and Mchugh, P.R. (1975) Mini-mental state: A practical method for grading the cognitive state of patients for the clinician. Journal of Psychiatric Research, 12, 96-98.

[15] Norton, E. (2000) Long-term care. In: Culyer, A.J. and Newhouse, J.P., Eds., Handbooks of Health Economics, North Holland, Amsterdam.
http://dx.doi.org/10.1016/S1574-0064(00)80030-X

[16] Portrait, F., Lindeboom, M. and Deeg, D. (2000) The use of long-term care services by the Dutch elderly. Health Economics, 9, 13-531.

http://dx.doi.org/10.1002/1099-1050(200009)9:6<513::AI D-HEC534>3.0.CO;2-R

[17] Cohen, M.A., Weinrobe, M. and Miller, J. (2000) Multivariate analysis of patterns of informal and formal caregiving among privately insured and nonprivately insured disabled elders living in the community. Agency for Health Care Policy and Research.

[18] Lu, J., Leung, G., Kwon, S., Tin, K.Y., Van Doorslaer, E. and O’Donnell, O. (2007) Horizontal equity in health care utilization-Evidence from three high-income Asian economies. Social Science and Medicine, 64, 199-212. http://dx.doi.org/10.1016/j.socscimed.2006.08.033

[19] Jeon, H. (2007) A comparative study of Korea's longterm care program. Thesis, Miami University, Oxford.

[20] Kwon, S., Kim, S.J. and Jung, Y. (2009) Introduction of long-term care insurance in South Korea. http://umdcipe.org/conferences/policy_exchanges/conf_p apers/

[21] Kang, I.O., Park, C.Y. and Lee, Y. (2012) Role of healthcare in Korean long-term care insurance. Journal of Korean Medical Science, 27, S41-S46. http://dx.doi.org/10.3346/jkms.2012.27.S.S41 